\title{
Voluntary Diving Exercise Improves Hippocampus-dependent Learning in Rats
}

\author{
RAHADIAN YUDO HARTANTYO*, HELEN EKO PUTRO, EPA YOHANA TOGA TOROP, \\ LAKSMINDRA FITRIA, MULYATI \\ ${ }^{1}$ Department of Tropical Biology, Faculty of Biology, Universitas Gadjah Mada \\ Jl. Teknika Selatan, Sekip Utara, Sleman, Yogyakarta, Indonesia. 55281 \\ *Email: rahadian.yudo@ugm.ac.id
}

Received 22 November 2019; Received in revised form 23 March 2020; Accepted 17 May 2020; Available online 30 June 2020

\begin{abstract}
Several physiological alterations that arise in response to hypoxemia conditions when diving are intended to protect oxygen-sensitive organs from the hypoxic condition. Hippocampus, known for its central function in memory formation, is sensitive to hypoxic conditions. This research aimed to study the effect of voluntary diving exercise (VDE) on the hippocampus-dependent learning performance of rats. Rats were divided into control and diving groups, with swim and voluntary diving exercises every day for 60 days, respectively. Observation of memory consolidation was carried out using Morris Water Maze (MWM) and Novel Object Recognition (NOR) tests. In the MWM test, the escape latencies in the diving group were shorter than those in the control group. Consistent results were obtained in the MWM probe trial which the time spent in the target quadrant was significantly longer in the diving group. Moreover, the diving group spent more time exploring the novel object in the NOR test. Based on the results, we can conclude that 60 days VDE significantly improves hippocampus-dependent learning capacity in trained rats.
\end{abstract}

Keywords: learning; memory; novel object; voluntary diving; water maze

\section{INTRODUCTION}

Feral rats (Rattus norvegicus) can naturally dive to search for underwater food in their habitat (McCulloch, 2012). They exhibit a physiological strategy to overcome breathing cessation during diving called diving response (Panneton, 2013). Diving causes low levels of oxygen in the blood or hypoxemia condition (Ridgway \& McFarland, 2006). On the other hand, the brain consumes $20 \%$ of the body's total oxygen consumption under normal condition (Spiotta et al., 2010; Fan et al., 2012), even though the brain only makes up $2 \%$ of the total body weight (Michiels, 2004). Furthermore, brain sensitivity on oxygen partial pressure changes is quite high, this sensitivity is mediated by astrocytes (Angelova et al., 2015; Marina et al., 2018; Takata et al., 2018).

Cell-level physiological response mechanism to hypoxic conditions is mediated by hypoxia-inducible factor (HIF-1) that plays a role in the regulation of the transcription level of other genes involved in the response to hypoxia: erythropoiesis-coding genes (Keswani et al., 2011; Agani et al., 2013), Fe-metabolism (Vigani, 2012; Guo et al., 2015), angiogenesis (Ahluwalia \& Tarnawski, 2012; Ahn et al.,
2014), aerobic glycolysis (Stubbs \& Griffiths, 2010; Semba et al., 2016), and growth factor (Wenger, 2002). Specific in the brain, hypoxic conditions lead to neuroglobin upregulation that possibly increases oxygen supply to the mitochondrial nerve cells (Burmester \& Hankeln, 2009).

Part of the brain that susceptible to hypoxic conditions is the hippocampus which plays an important role in memory formation (Ridgway \& McFarland, 2006; Macri et al., 2010). Memory formation consists of three distinct mechanisms: encoding, consolidation, and retrieval of the information (Straube, 2012). Scientists have divided memory into several distinct memory systems based on how our brain process the information: semantic, episodic, working, and procedural memories (Matthews, 2015). In recent research, we assessed spatial and recognition memory as part of the episodic memory category.

Several investigations have been conducted to elucidate brain protection against hypoxic conditions using forced submersion animals (Panneton et al., 2010). It has been questioned that the hypoxic conditions in forced diving can affect the diving responses. 
However, the effect of prolonged voluntary diving exercise on memory function is still unknown. Therefore, this research aimed to investigate the memory consolidation performance in rats after 60 days of voluntary diving exercise (VDE).

\section{MATERIALS AND METHODS}

Animals, housing, and ethical statement. Female rats (Rattus norvegicus Berkenhout, 1769) Wistar strain from Universitas Gadjah Mada Integrated Research and Testing Laboratory were acclimated at the animal facility in the Faculty of Biology, Universitas Gadjah Mada. Rats were housed in standard cages $(40 \times 30 \times 20 \mathrm{~cm})$ with standard pellet food and tap water ad libitum. The cages contained wood-chip bedding and were maintained in constant temperature $\left(26-27^{\circ} \mathrm{C}\right)$ and humidity (76-88\%) on a 12 hour light/dark cycle. The animal experimental protocol was approved by the Institutional Animal Ethics Committee (IAEC) of Universitas Gadjah Mada (Ref. 00059/04/LPPT/V/2018).
Animal Treatment. Twenty female rats were divided into control (CNT) and treatment (DIV) group. The voluntary diving exercise was carried out by training rats to dive periodically for 60 days (five days in a week). Meanwhile, CNT rats were trained to swim in similar distances with DIV rats. The diving chamber was built from glass material with $100 \times 30 \times 20 \mathrm{~cm}^{3}$ dimension, separated into twin connected tracts (total $200 \mathrm{~cm}$ length). The chamber was filled with tap water and maintained at $30-32^{\circ} \mathrm{C}$. In the diving exercise, the water surface was covered with plexiglass to avoid the rats inhaling surface air. Meanwhile, in the swimming exercise (CNT), the cover was opened. Rats were trained to dive constantly for $200 \mathrm{~cm}$ length. As the introduction to start module, rats were lowered slowly using a manual elevator. Rats were then left to exit and swim to the finish module. After several days, the water level was raised to cover the exit way of the start module. Diving training completed when rats can escape from the start module then dive into the finish module (Figure $1)$.

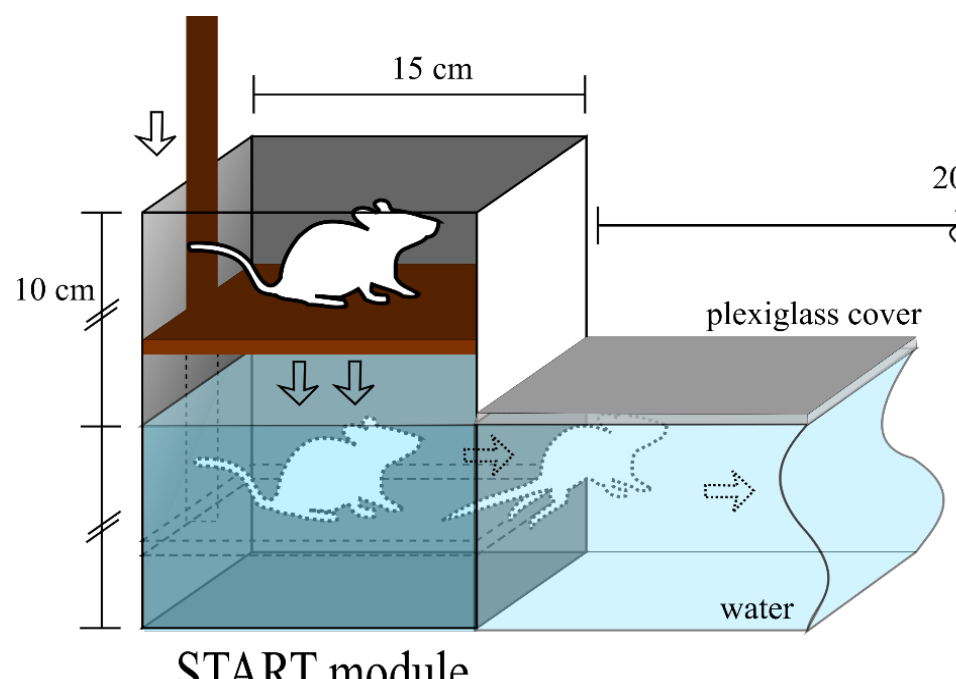

START module

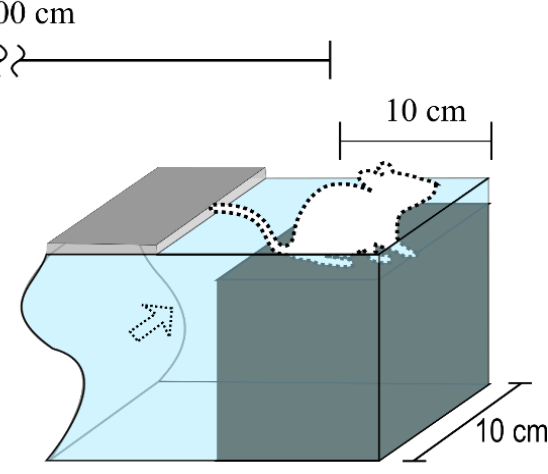

FINISH module

Figure 1. Rats VDE apparatus design. Start module design consisted of a manual elevator and a submerged exit way. The diving/swimming distance was $200 \mathrm{~cm}$ length, from the start module to the finish module.

MWM tests. Morris water maze (MWM) tests were conducted using a black-colored circular tank (diameter: $150 \mathrm{~cm}$; height: $50 \mathrm{~cm}$ ) filled with tap water $\left(30-32^{\circ} \mathrm{C}\right)$. The start or finish platform was created from clear glass (10 $\mathrm{x} 10 \mathrm{x} 15 \mathrm{~cm})$. Rats swimming trajectories were recorded using B-PRO5 $\alpha$ fixed focus F2.8 $\mathrm{f}=3$ $\mathrm{mm}$ 170o wide-angle lens (Brica, China) then computed using Idtracker 2.1 (Cajal Institute, Madrid, Spain). We measured duration of rats exploring novel and familiar objects using the Preference Index (PI) i.e. a percentage of the 
time spent by rats exploring novel objects divided by total exploration time. The MWM tests were carried out for five consecutive days in sequence: training trial, probe trial, and visual cue trial (Vorhees \& Williams 2006). On the first day training, the rat was released in the tank at four random points with a visible platform (above the water). On day two until four, training trials were conducted with the hidden (submerged) platform. Escape latency for each trial was recorded from release time until rats reach the finish platform. On day 5, a probe trial task was performed by allowing to swim in the tank for $60 \mathrm{~s}$ without the platform. The duration spent in the target/platform quadrant was recorded. Subsequently, a visual cue test was performed, the platform was returned into the visible condition and the escape latency was recorded.

NOR tests. Novel object recognition (NOR) tasks were carried out for four consecutive days: familiarization, habituation, and test day (Antunes and Biala, 2012). In familiarization, a rat was released in the test box (40 × $40 \times 40 \mathrm{~cm}$, black colored) for five minutes. Habituation was conducted by placing two identical objects in the box for five minutes duration on two consecutive days. Afterward, the test day was performed by replacing one object with another novel object for $60 \mathrm{~s}$. The time spent by the rat to explore the novel object divided with total exploration time was determined as a preference index (PI).

Statistical Analysis. All data were analyzed using SPSS 22.0 (IBM corporation, USA) for Independent T-test, ANOVA, MannWhitney U test, and Tuckey test. Tests were considered significant at $\mathrm{p}<0.05$.

\section{RESULT AND DISCUSSION}

Spatial memory is correlated to brain function in preserve information about the location of any physical stimuli regarding body position (egocentric) and external space (allocentric) (Paul, et al., 2009). In the MWM tests, rats create a spatial memory using external visual information around the chamber. Memory was assessed by the duration before the animal find the platform (escape latency) and by the percentage of the time spent in the target quadrant. During day-5 MWM test, the escape latencies of DIV rats $(5.27 \pm 0.43 \mathrm{~s})$ were shorter than those in CNT rats $(6.77 \pm 1.85$ s). The results of the Mann-Whitney $U$ test showed there was no significant difference in escape latency between groups at day-5 MWM ( $p>0.05)$ (Figure 2a).

Subsequently, a probe trial was conducted on day-5 training for one minute total duration to assess spatial memory. Swimming trajectories of rats at the MWM probe trial showed normal movement path of CNT and DIV rats along the target quadrant (Figure 3a). However, the time spent in the target quadrant of DIV rats $(46.32 \pm 1.80 \%)$ were significantly longer than those in CNT rats $(34.85 \pm 3.34 \%)$ ( $\mathrm{p}<0.05$ ) according to Independent T-test (Figure 3b).

To assess that the results of MWM tests on memory performance were not affected by sensorimotor function, we performed the MWM visual cue test. The test was conducted after the MWM probe trial on day-5 of training. Statistical analysis using the Mann-Whitney U test showed no significant result of escape latencies in CNT and DIV rats during MWM visual cue test (Figure 2b).

We used MWM tests to assess hippocampus-dependent learning without being affected by external motivation such as food. The escape latencies in the DIV rats were shorter than those in the CNT rats, indicating that the learning capacity was increased after subchronic VDE. Moreover, consistent results were obtained in MWM probe trial, in which the time spent in the target quadrant was significantly longer in the diving group. The sensorimotor factor can be ignored because no significant result has been found in the MWM visual cue tests. 


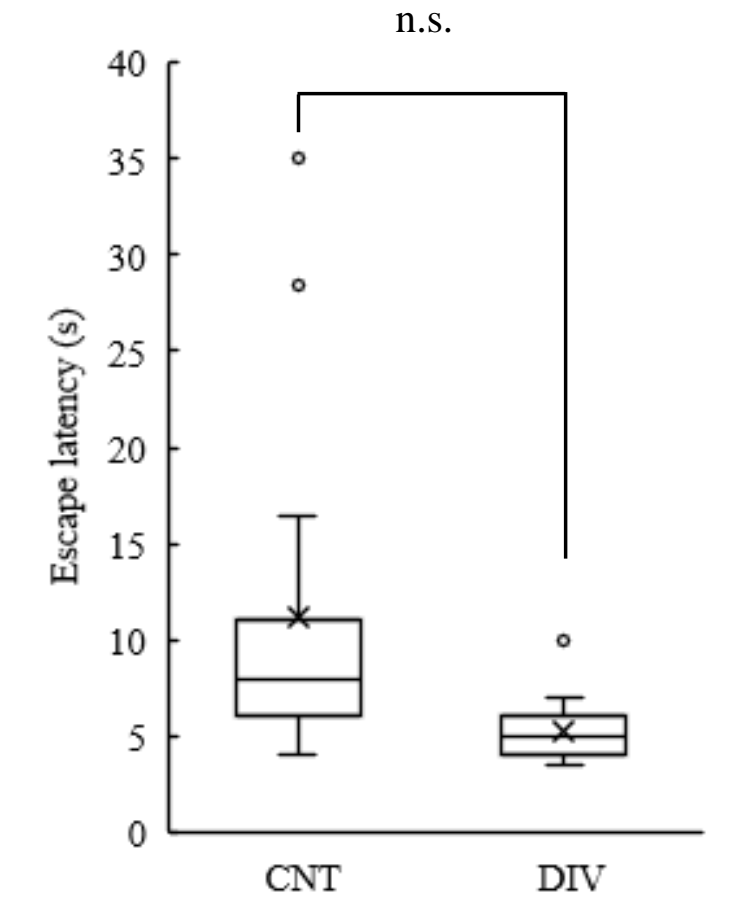

a

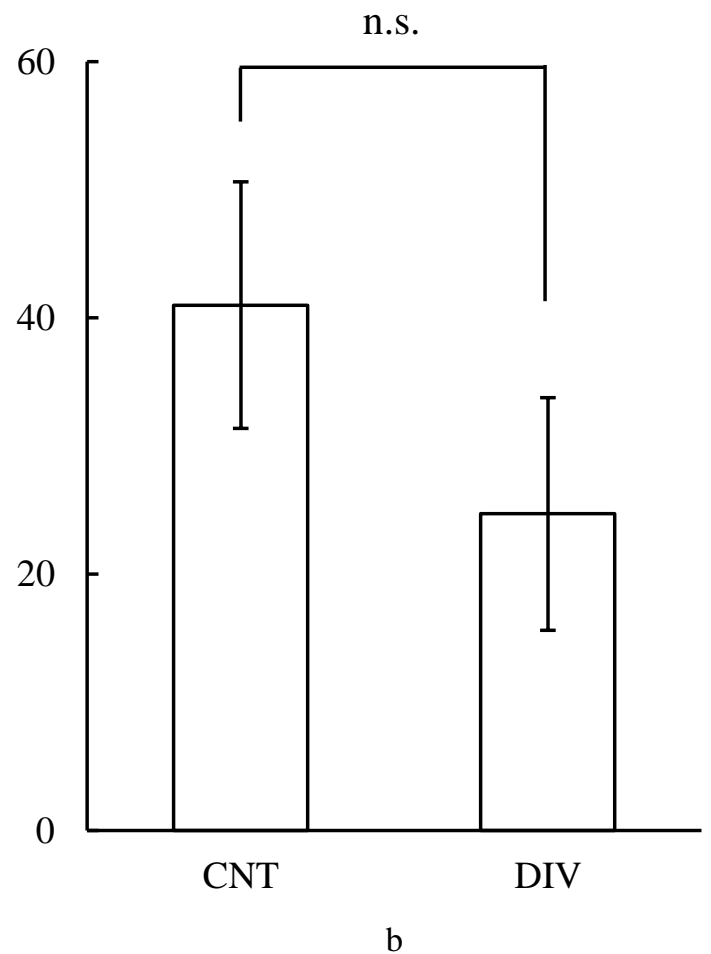

Figure 2. Performance of CNT and DIV rats during day-5 MWM test and MWM visual cue test: a. Escape latency of DIV rats was shorter than CNT rats at day-5 MWM test using invisible platform but statistically no significant (n.s., $\mathrm{p}>0.05$, Mann-Whitney $\mathrm{U}$ test). Data are presented as mean $(\times)$ and median with upper and lower quartiles, min and max values and outliers (o). $n=5$ for all groups; b. MWM visual cue test showed no significant result of CNT and DIV rats (n.s., p > 0.05, Mann-Whitney U test). Data are presented as mean \pm S.E.M. $\mathrm{n}=5$ for all groups. CNT: control group; DIV: diving group.

In addition to the MWM, the rats were subjected to NOR tasks, which also evaluate hippocampus-dependent learning, especially recognition memory. Recognition memory is the capability to consider whether a recent object has been presented before, this system consists of two parts: recollection and familiarity (Squire et al., 2007). We observed the duration of rats exploring novel and familiar

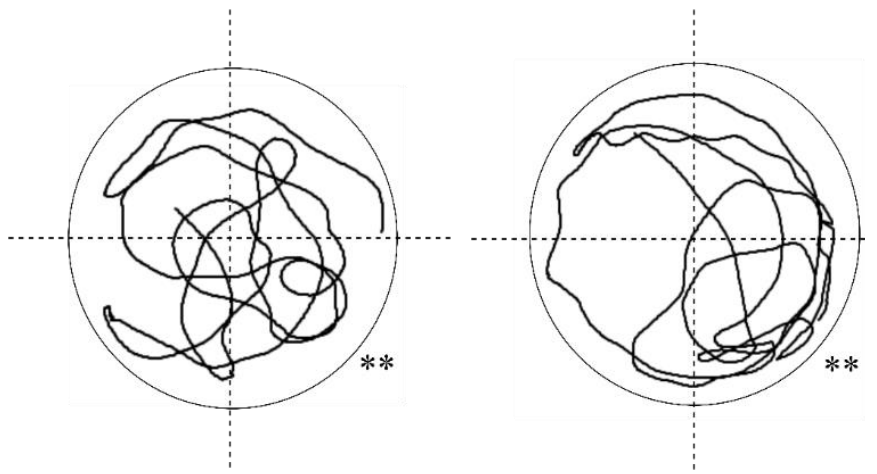

objects. PI of DIV rats $(85.11 \pm 14.88 \%)$ were significantly higher than those in CNT rats $(55.46 \pm 10.42 \%)$, based on Independent T-test $(\mathrm{p}<0.05)$ (Table 1). It means that the DIV rats spent more time exploring the novel object. Furthermore, rats of all groups have sufficient motivation to learn, since there is no significant result in the total exploration time $(\mathrm{p}>0.05)$.

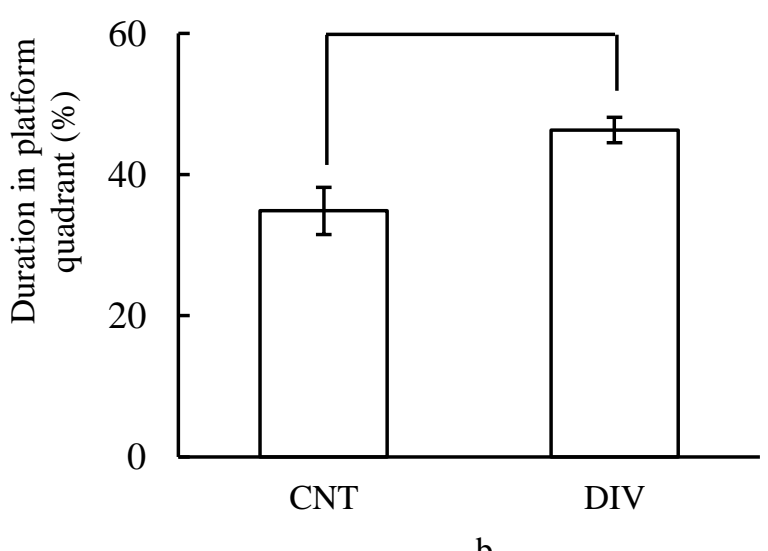

b 
Figure 3. Swim trajectories and time spent in the target quadrant during MWM probe trial: a. Representative example of individual swimming trajectories of CNT and DIV rats during MWM probe trial using a circular chamber (150 $\mathrm{cm}$ in diameter). Asterisk (**) indicates the quadrant of escape platform position that have removed in this probe trial; b. Time spent in the target quadrant of DIV rats was significantly shorter than those in CNT rats at MWM Probe trial ( $\mathrm{p}<0.05$, Independent T-test). Data are presented as mean \pm S.E.M. $\mathrm{n}=6$ for all groups. CNT: control group; DIV: diving group.

Rat physiological responses to diving are different than those in swimming. In the diving state, they exhibit a decrease in arterial pressure and heart rate (Hult et al., 2019). Therefore, a diving rat is susceptible to hypoxemia condition i.e. low oxygen level in their blood. Hypoxemia condition is not always related to brain hypoxia
(Ridgway \& McFarland, 2006). Therefore, brain cell necrosis related to hypoxemia may not occur unless in prolonged dive. Hooded Seals (a diving mammal) show a lower aerobic capacity of the brain when they undergo long dives, which may be assumed as an energysaving strategy (Fabrizius et al., 2016).

Table 1. Preference index and exploration time of CNT and DIV rats during NOR test

\begin{tabular}{ccc}
\hline \multirow{2}{*}{ Groups } & \multicolumn{2}{c}{ NOR parameters } \\
\cline { 2 - 3 } & Preference Index (\%) & Exploration time (s) \\
\hline CNT & $55.46 \pm 10.42$ & $12.93 \pm 5.54$ \\
\hline DIV & $85.11 \pm 14.88 *$ & $13.27 \pm 3.46^{\text {n.s. }}$
\end{tabular}

CNT: control group; DIV: diving group; *: significant to CNT ( $p<0.05$ Independent T test); n.s.: not significant to CNT ( $<<0.05$ Independent $\mathrm{T}$ test)

VDE mimics an intermittent hypoxia condition in rats' brains. As the diving duration in the current research was short, neurons in the brain may only undergo transient hypoxia. Our results showed that this condition improves memory performance in rats and is consistent with previous research about an improvement of memory in rat's hippocampus (Bouslama et al., 2015).

Repetitive acute intermittent hypoxia also increases neurotrophic factors in motor neuron (Satriotomo et al., 2016). Furthermore, neural plasticity is modulated by neurotrophic factors such as brain-derived neurotrophic factor (BDNF)(Castrén \& Antila, 2017). The brain conducts plasticity through various stimuli regarding learning and memory which modifies the brain structures, functions, and connections (Mateos-Aparicio \& Rodríguez-Moreno, 2019). However, further investigations need to be conducted to elucidate molecular and neurophysiological mechanisms underlying the increase of memory consolidation performance due to repeated hypoxia exercise.

\section{CONCLUSION}

Based on the results, it can be concluded that the subchronic voluntary diving exercise indicates improvements in hippocampusdependent learning in rats.

\section{ACKNOWLEDGMENTS}

The research on Voluntary Diving Exercise on Learning and Memory of Rats was supported by BPPTNBH Faculty of Biology Universitas Gadjah Mada Grant UGM/BI/1670/M/05/01 awarded to RYH. The authors declare that there is no conflict of interest regarding this article.

\section{REFERENCES}

Agani F, Jiang BH. 2013. Oxygen-independent regulation of HIF-1: novel involvement of $\mathrm{PI} 3 \mathrm{~K} / \mathrm{AKT} / \mathrm{mTOR}$ pathway in cancer. Current cancer drug targets. vol 13(3): 245-251.

Ahluwalia A, Tarnawski AS. 2012. Critical role of hypoxia sensor-HIF-1 $\alpha$ in VEGF gene activation. Implications for angiogenesis and tissue injury healing. Current medicinal chemistry. vol 19(1): 90-97. doi: https://doi.org/10.2174/092986712803413944.

Ahn GO, Seita J, Hong BJ, Kim YE, Bok S, Lee CJ, Kim KS, Lee JC, Leeper NJ, Cooke JP, Kim HJ, Kim IH, Weissman IL, Brown JM. 2014. Transcriptional activation of hypoxia-inducible factor-1 (HIF-1) in myeloid cells promotes angiogenesis through VEGF and S100A8. Proceedings of the National Academy of Sciences. vol 111(7): 2698-2703. doi: https://doi.org/10.1073/pnas.1320243111.

Angelova PR, Kasymov V, Christie I, Sheikhbahaei S, Turovsky E, Marina N, Korsak A, Zwicker J, 
Teschemacher AG, Ackland GL, Funk GD, Kasparov S, Abramov AY, Gourine AV. 2015. Functional oxygen sensitivity of Astrocytes. Journal of Neuroscience. vol 35(29): 10460-10473. https://doi.org/10.1523/JNEUROSCI.004515.2015.

Antunes M, Biala G. 2012. The novel object recognition memory: Neurobiology, test procedure, and its modifications. Cognitive Processing. vol 13(2): 93110. https://doi.org/10.1007/s10339-011-0430-z.

Bouslama M, Adla-Biassette $\mathrm{H}$, Ramanantsoa N, Bourgeois T, Bollen B, Brissaud O, Gallego J. 2015. Protective effects of intermittent hypoxia on brain and memory in a mouse model of apnea of prematurity. Frontiers in Physiology. vol 6(313): 111. https://doi.org/10.3389/fphys.2015.00313.

Burmester T, Hankeln T. 2009. What is the function of neuroglobin?. Journal of Experimental Biology. vol 212(10):

1423-1428. https://doi.org/10.1242/jeb.000729.

Castrén E, Antila H. 2017. Neuronal plasticity and neurotrophic factors in drug responses. Molecular Psychiatry. $\quad$ vol 22(8): 1085-1095. https://doi.org/10.1038/mp.2017.61

Fabrizius A, Hoff MLM, Engler G, Folkow LP, Burmester T. 2016. When the brain goes diving: Transcriptome analysis reveals a reduced aerobic energy metabolism and increased stress proteins in the seal brain. BMC Genomics. vol 17(1): 1-11. https://doi.org/10.1186/s12864-016-2892-y.

Fan AP, Benner T, Bolar DS, Rosen BR, Adalsteinsson E. 2012. Phase-based regional oxygen metabolism (PROM) using MRI. Magnetic resonance in medicine. vol 67(3): 669-678. doi: https://doi.org/10.1002/mrm.23050.

Guo C, Zhang YX, Wang T, Zhong ML, Yang ZH, Hao LJ, Chai R, Zhang S. 2015. Intranasal deferoxamine attenuates synapse loss via up-regulating the P38/HIF-1 $\alpha$ pathway on the brain of APP/PS1 transgenic mice. Frontiers in aging neuroscience. vol 7: 1-12. doi: https://doi.org/10.3389/fnagi.2015.00104.

Hult EM, Bingaman MJ, Swoap SJ. 2019. A robust diving response in the laboratory mouse. Journal of Comparative Physiology B: Biochemical, Systemic, and Environmental Physiology. vol 189(3): 685692. https://doi.org/10.1007/s00360-019-01237-5.

Keswani SC, Bosch-Marcé M, Reed N, Fischer A, Semenza GL, Höke A. 2011. Nitric oxide prevents axonal degeneration by inducing HIF-1-dependent expression of erythropoietin. Proceedings of the National Academy of Sciences. vol 108(12): 49864990. https://doi.org/10.1073/pnas.1019591108.

Macri MA, D’Alessandro N, Di Giulio C, Di Iorio P, Di Luzio S, Giuliani P, Pokorski M. 2010. Regionspecific effects on brain metabolites of hypoxia and hyperoxia overlaid on cerebral ischemia in young and old rats: a quantitative proton magnetic resonance spectroscopy study. Journal of biomedical science. vol 17(1): 1-19. https://doi.org/10.1186/1423-0127-17-14.

Mateos-Aparicio P, Rodríguez-Moreno A. 2019. The impact of studying brain plasticity. Frontiers in Cellular Neuroscience. vol 13(16): 1-5. https://doi.org/10.3389/fncel.2019.00066.

Marina N, Turovsky E, Christie IN, Hosford PS, Hadjihambi A, Korsak A, Ang R, Mastitskaya S, Sheikhbahaei S, Theparambil SM, Gourine AV. 2018. Brain metabolic sensing and metabolic signaling at the level of an astrocyte. Glia. vol 66(6): 1185-1199. doi: https://doi.org/10.1002/glia.23283.

Matthews BR. 2015. Memory dysfunction. Continuum Lifelong Learning in Neurology. vol 21(3): 613626.

https://doi.org/10.1212/01.CON.0000466656.5941 3.29 .

McCulloch PF. 2012. Animal models for investigating the central control of the mammalian diving response. Frontiers in Physiology. vol 3(169): 116. https://doi.org/10.3389/fphys.2012.00169

Michiels C. 2004. Physiological and pathological responses to hypoxia. The American Journal of Pathology. vol 164(6): 1875-1882. https://doi.org/10.1016/S0002-9440(10)63747-9.

Panneton WM. 2013. The Mammalian diving response: an enigmatic reflex to preserve life? Physiology. vol 28(5): https://doi.org/10.1152/physiol.00020.2013.

Panneton WM, Gan Q, Juric R. 2010. The rat: a laboratory model for studies of the diving response. Journal of Applied Physiology. vol 108(4): 811820. https://doi.org/10.1152/japplphysiol.00600.2009.

Paul CM, Magda G, Abel S. 2009. Spatial memory: Theoretical basis and comparative review on experimental methods in rodents. Behavioural Brain Research. vol 203(2): 151-64. https://doi.org/10.1016/j.bbr.2009.05.022.

Ridgway L, McFarland K. 2006. Apnea diving: longterm neurocognitive sequelae of repeated hypoxemia. The Clinical Neuropsychologist. vol 20(1): $160-176$. https://doi.org/10.1080/13854040590947407.

Satriotomo I, Nichols NL, Dale EA, Emery AT, Dahlberg JM, Mitchell GS. 2016. Repetitive acute intermittent hypoxia increases growth/neurotrophic factor expression in non-respiratory motor neurons. Neuroscience. $\quad$ vol 322: 479-488. https://doi.org/10.1016/j.neuroscience.2016.02.060

Semba H, Takeda N, Isagawa T, Sugiura Y, Honda K, Wake M, Hidenobu Miyazawa H, Yamaguchi Y, Miura, Jenkins DMR, Choi H,Kim JW, Asagiri M, Cowburn AS, Abe H, Soma K, Koyama K, Katoh M, Sayama K, Goda N, Johnson RS, Manabe I, Nagai R, Komuro I. 2016. HIF-1 $\alpha$-PDK1 axisinduced active glycolysis plays an essential role in macrophage migratory capacity. Nature communications. vol 7: 1-10. doi: 
https://doi.org/10.1038/ncomms11635.

Spiotta AM, Stiefel MF, Gracias VH, Garuffe AM, Kofke WA, Maloney-Wilensky E, Troxel AB, Levine JM, Le Roux PD. 2010. Brain tissue oxygen-directed management and outcome in patients with severe traumatic brain injury. Journal of neurosurgery. vol 113(3): 571-580. doi: https://doi.org/10.3171/2010.1.JNS09506.

Squire LR, Wixted JT, Clark RE. 2007. Recognition memory and the medial temporal lobe: A new perspective. Nature Reviews Neuroscience. vol 8(11): 872-883. https://doi.org/10.1038/nrn2154.

Straube B. 2012. An overview of the neuro-cognitive processes involved in the encoding, consolidation, and retrieval of true and false memories. Behavioral and Brain Functions. vol 8(35): 1-12. https://doi.org/10.1186/1744-9081-8-35.

Stubbs M, Griffiths JR. 2010. The altered metabolism of tumors: HIF-1 and its role in the Warburg effect. Advances in enzyme regulation. vol 50(1): 44-55. doi: 10.1016/j.advenzreg.2009.10.027.

Takata N, Sugiura Y, Yoshida K, Koizumi M, Hiroshi N, Honda K, Ryutaro Yano R, Komaki Y, Matsui K, Suematsu M, Mimura M, Okano H, Tanaka KF. 2018. Optogenetic astrocyte activation evokes BOLD fMRI response with oxygen consumption without neuronal activity modulation. Glia. vol 66(9): 2013-2023. doi: https://doi.org/10.1002/glia.23454.

Vigani G. 2012. Does a similar metabolic reprogramming occur in fe-deficient plant cells and animal tumor cells?. Frontiers in plant science. vol 3: $1-4$. doi: https://doi.org/10.3389/fpls.2012.00047.

Wenger RH. 2002. Cellular adaptation to hypoxia: O2sensing protein hydroxylases, hypoxia-inducible transcription factors, and O2-regulated gene expression. The FASEB Journal. vol 16(10): 11511162. https://doi.org/10.1096/fj.01-0944rev. 